\title{
EDITORIAL
}

\section{How Technologies are Shaping the Future?}

Journal of Revenue and Pricing Management (2006) 5, 1. doi:10.1057/palgrave.rpm.5160025

Technology is the driver that has revolutionised revenue management and pricing, making it accessible in the terms of cost, knowledge and time to the advantage of consumers, business and management. Those early days of big main frames are no more. Technology has being on an exponential curve driven by the forces of Moore's Law. The six key drivers of this force are, firstly, is the movement to real time - a transition from mainframe to the microcomputer. The second component is meta-bytes. This is information about information. The third represents the embedded technology revolution, which is populating the world with devices so small that they are invisible to the naked eye. The forth component is the business system, which has evolved in such a manner in which information is freely exchanged. The fifth component is the rise of information that moves us from the present to the future, and finally the sixth element is Moore's Law itself, which is the acceleration of all information. The resulting explosion enables revenue management science to become mainstream. In this issue, we show how technology has revolutionised the practice of revenue management

Irene $\mathrm{Lg}$ leads the research papers section with a topical insight into differentiation and selfselection, suggesting that companies must incorporate economic and marketing concepts through deploying dynamic service differentiation so that consumer needs are met more closely. Through dynamic service differentiation, service attributes are changed dynamically according to the preferences of consumers, thereby influencing demand and distribution. Thus, allowing the market to self-select, businesses are able to be more precise and derive higher revenues. Guillermo Gallego and co-workers consider dynamic games between two providers, which has implications for revenue management providers who have dynamic competitive interactions rather a static relationship. Juha Munnukka explores the pricing methods applied to charging mobile service customers, through an empirical analysis is able to determine the relationship of pricing methods and pricing perceptions. Sara Yaipairoj and Fotios Harmantzis paper highlights auctionbased pricing models for performance and revenue optimisation. Their research looks at problems of congestion, suggesting an admission control mechanism as a possible solution. Paat Rusmevichietong and co-workers research the opportunities and challenges of using preference data for vehicle pricing, a case study of General Motors. Michael Frank and co-workers use an event-driven stochastic simulation model to mirror a real world revenue management system - the purpose being to evaluate revenue impacts of a continuously adjusted assignment during a given booking period.

In the practice papers and futures section, Venkaeshwara Rao and Barry Smith explore models of travel retailing and e-commerce, discussing a decision support framework for an online travel agency. Marco Truffelli examines the phenomena of dynamic packaging and pricing, whereas Robert Shumsky elaborates the SouthWest effect and how it reshaped airline alliances and revenue management. To conclude, technology has certainly revolutionised revenue management!

\section{Ian Yeoman \\ Editor}

E-mail: Ian.Yeoman@visitscotland.com 